\title{
Economics Teachers' Topic Specific Pedagogical Content Knowledge Model for teaching Market Dynamics
}

\author{
Ijeoma C. Ogbonnaya, Andile Mji, \\ Olivia N. Mafa-Theledi and Beatrice Ngulube \\ Tshwane University of Technology, South Africa \\ https://orcid.org/0000-0002-9308-1625 \\ https:// orcid.org/0000-0002-3077-9209 \\ https:/ / orcid.org/0000-0001-8971-4525 \\ https://orcid.org/0000-0001-5631-9094
}

\begin{abstract}
The teaching and learning of Market Dynamics (MD) seems to be a challenging topic for teachers and learners. This research aimed to develop an Economics Teachers' Topic Specific Pedagogical Content Knowledge (ET-TSPCK) Model to improve the teaching of MD. Mavhungas' Topic Specific Pedagogical Content Knowledge (TSPCK) model was adapted as the base model to identify Economics Topic Specific Pedagogical Content Knowledge (ETSPCK) components for teaching MD. Using a descriptive case study design, a purposeful sample of two economics teachers of the $10^{\text {th }}$ and $11^{\text {th }}$ grades were used for the research. While lesson observations were used as data collection method, data were analyzed using a qualitative data analysis technique, namely thematic analysis. Economics teachers' topic specific knowledge usable for teaching MD were identified and the model "Economics Teachers' Topic Specific Pedagogical Content Knowledge (ET-TSPCK) model" was developed. In addition, it was found that there exists an interrelationship among the ETSPCK components. However, the relationship between the teaching strategies and the components of Curriculum knowledge were not connected and fully developed in the participating teachers. The model provides insights into the implementation of the Curriculum Assessment Policy Statement (CAPS) with reference to the teaching of MD hence, suggesting ways in which the teaching of the topic could be improved.
\end{abstract}

Keywords: economics topic specific pedagogical content knowledge; economics teachers; market dynamics; model

\section{Introduction}

In many developing countries such as South Africa, the teaching and learning of Market Dynamics (MD) seems to be a challenging topic. From South African 
perspective, learners face challenges in understanding MD. Evidence from the last 2015 test of economics literacy held in South Africa on learners' understanding of basic economics concepts showed that learners struggle with most basic economics concepts contained in the Test of Understanding Economics in South Africa (TUESA) (Fourie \& Krugell, 2015). Learners were tested on MD concepts such as demand, supply and elasticity in MD and the TUESA results showed that learners performed least with 46.38 per cent score in microeconomics (Fourie \& Krugell, 2015).

Consequently, the Diagnostic report for Matric exam question analysis showed that learners have not performed well on questions related to $M D$ in Microeconomics Paper-2 over the years (DBE, 2020). (Matric exam is the final and exit examination for the $12^{\text {th }}$ Grades). For example, the analysis of matric exam questions for 2019 reported: "Candidates performed poorly on questions related to microeconomics... the supply curve is not covered explicitly in the content but rather the demand curve" (DBE, 2020. P. 95). Microeconomics questions in South African matric exams are based on MD. While the poor learners' understanding of MD could be attributed, at least in part, to teachers' poor Topic Specific Knowledge of MD teaching, the gap that appears to exist in the South African context was the absence of a seemingly valid model for teaching MD to South African learners.

Research evidence from other countries also showed that learners lack conceptual understanding of Market Dynamics concepts (Ayers, 2015; Aguiló, Sard \& Tugores, 2016) and often considered the topic dry and overly mathematical (Ayer, 2015).

Indeed, research on economics teachers' use of TSPCK models for teaching specific economics topics is still an emerging field. A number of PCK studies in economics education have focused mainly on pre-service teachers' PCK development (Ayers, 2016; Kuhn, Alonzo \& Zlatkin-Troitschanskaia, 2016; Kruger, 2018 and $\mathrm{Ng} \&$ Chan, 2014), instead of looking into how to improve the teaching and learning of specific topics using TSPCK models.

In the science education domain, a considerable amount of research have been conducted (Aydin, Friedrichsen, Boz \& Hanuscin, 2014; Mavhunga \& Rollnick, 2016) on teachers' use of TSPCK models to improve the teaching of specific topics. The findings from these researches showed that the use of TSPCK models for teaching specific science topics facilitated both teachers and learners' understanding of those challenging topics and contributed to teachers' professional development (Akinyemi, 2016; De Jager, 2015; Rollinick \& Mavhunga, 2016). However, despite the rich research findings in the science education domain on the effectiveness of TSPCK models for teaching specific topics, no such research has been conducted to understand the effectiveness of TSPCK models for teaching MD. 


\subsection{Market Dynamics}

Market Dynamics (MD) is the interaction between the forces of demand and supply and the prices they generate. Malyshkin (2016) describes MD as "The disbalance of Supply and Demand that is typically considered as the driving force of the markets". From school perspective, MD is one of the fundamental economics topics consisting of the basic economics concepts that play an important role in understanding other economics concepts. The topic cuts across a range of topics in the social science subject domains and falls in the second term of the Curriculum and Assessment Policy Statement (CAPS) - economics for the Further Education and Training (FET) bands, Grades 10 to 12 levels. A cursory check shows that MD occupies topical positions in school economics curriculum in most volumes and most of its concepts fill much of the economics topics in the FET bands.

MD concepts such as demand, supply, price etc., are expressed in different forms. They can be visualised in the form of graphs or represented in symbols. For example, the concept of demand could be presented as a demand function, $\mathrm{Qd}=\mathrm{f}(\mathrm{P}, \mathrm{Y}, \mathrm{Ps}, \mathrm{A}$, etc. $)$ and that of supply as a supply function; $\mathrm{Qs}=\mathrm{f}(\mathrm{P}, \mathrm{P} 1, \mathrm{P} 2$, $\mathrm{G}$, etc). MD also consists of the Demand and Supply (DD-SS) model that gives a clearer understanding of the market structures. Without the fundamental understanding of the model, it is almost impossible to understand the complex world of economic theory. The DD-SS model is one of the economic reasoning tools that enable economics learners to "think like economist" (Mankiw, 2015; Zuidhof, 2014). Indeed, teachers' understanding of MD is important for learners' performance hence, a need of an economics model to improve MD teaching.

\subsection{TSPCK Models}

TSPCK models are discussed in order to establish reasons for ET-TSPCK model for MD teaching and to enable a detailed analysis of economics teachers' topic specific knowledge to be carried out. Shortly after Shulman (1986) groundbreaking PCK model of teachers' knowledge base for teaching, the PCK model was re-conceptualized in its' topic specific forms by different researchers (e.g. Grossman, 1990; Cochran, DeRuiter \& King, 1993; Magnusson, Krajcik \& Borko, 1999; Veal \& Makinster, 1999; Carlsen, 1999; Gess-Newsome's, 1999), thus making TSPCK models a unique construct from PCK model.

Veal and Makinster (1999) developed two PCK taxonomy models where knowledge is arranged in different levels. The first PCK taxonomy shows circles of different PCK level that overlap one another and ordered thus: General PCK, Domain-specific PCK and Topic-specific PCK. Veal and Makinster refer to Topic-Specific PCK as a specific knowledge necessary to teach a topic in a domain. Veal and Makinstar (1999) later modified the first taxonomy by presenting it in a pyramid form thus forming a "hierarchical structure of PCK and its attributes". Both models speak specifically to teachers' knowledge of the content of a specific topic in the domain and provide insight into the importance of topic-specific PCK. The models also noted that "the most specific and novel level of the general taxonomy (of PCK) is topic specific PCK" (p. 9). However, in 
Veal and Makinstar (1999) newly modified model, there seems to be no interaction between the components of the model. Each component stands on its own base on the pyramid. Consequently, the modified model failed to show the transformative aspect of the content knowledge.

Magnusson, Krajcik and Borko (1999) model was known for its transformative knowledge and was developed from an integrative view. The model is made up of five components: Knowledge of assessment, Knowledge and beliefs about science curriculum, orientation to teaching science, knowledge of students' understanding of science and knowledge of instructional strategies. Knowledge of instructional strategies includes knowledge of topic specific strategies and knowledge of subject specific strategies. However, a closer look at the model shows that all other components interact with 'orientation to science teaching' only but there seems to be no interaction among each of the components. In particular, the integrative view did not penetrate the knowledge of topic specific strategies. One of the gaps this present study intends to close in Magnusson et al. (1999) model is to bring to the fore content knowledge, which seems to be hidden in Magnusson et al. (1999) model.

Park and Oliver (2008)'s PCK model known as Hexagon Model extended Magnusson et al. (1999) models' components by adding self-efficacy as another PCK component. The model consists of eleven components with so many subcomponents. Among the components is knowledge of instructional strategies for teaching science, which has topic specific strategies and subject specific strategies as sub-component. The problem with the model is that it failed to clarify the boundary of PCK from other categories of teachers' knowledge. For example, self-efficacy may not necessary be considered as a knowledge component per se rather as one's personal character and how it in-relate with topic specific strategies is not well specified.

From the foregoing, it is clear that the existing models are not deemed fit to be used as base models after considering their limitations. We were therefore led to choose a model that has the basic components closer to what is needed to develop our new model.

\subsection{Theoretical Framework}

Among the TSPCK models developed by different researchers, of special importance is Mavhunga (2012) TSPCK model (See Figure 1) noted for its most contributions to Topic Specific studies. Mavhunga (2012) TSPCK model recognized that specific knowledge is needed for transforming the content knowledge in a particular topic into teachable form using pedagogical reasoning. The model was also noted for its' transferability principles, that is, that although the principle of TSPCK can be transferred across topics, Topic Specific Knowledge in a particular topic is not transferable from one topic to another (Mavhunga, 2012; Rollnick \& Mavhunga 2013). This implies that the principles of topic specific could be applied for any topic in any field of study. 
Mavhunga (2012) model is made up of the five basic components that could serve as the bases for our new model development. These are: Learners' Prior Knowledge (LPK), Curricular Saliency (CS), Content Knowledge (CK), Knowledge of Representations (KoR) and Teaching Strategies (TS). Mavhunga (2012) defined these components as follow; LPK are common and widely researched teachers' knowledge of learners' conceptions, preconceptions and misconceptions and learners' pre-existing knowledge. CK involves teachers' understanding of what makes a topic easy or difficult to teach or learn. Teaching strategies involves using effective instructional strategies for particular misconceptions, and for known areas of difficulty to learn. Curricular saliency is the ability to analyse and organize a topic for purposes of planning for teaching, while representations are various ways of representing subject matter with examples, illustrations, analogies, simulations, diagrams, tables, and models.

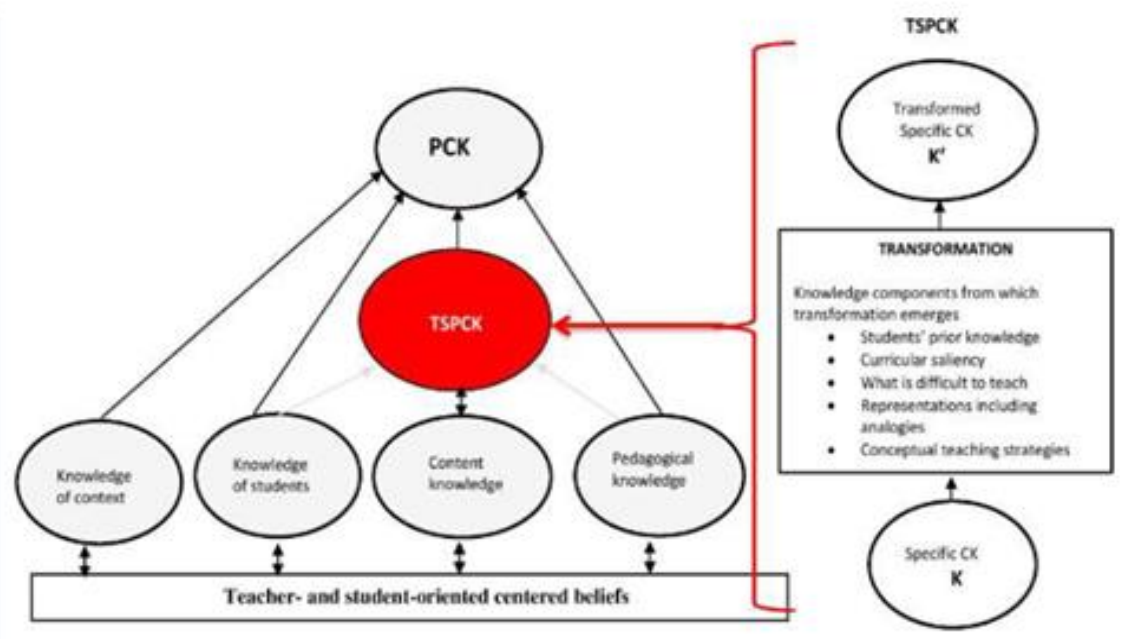

Figure 1: Mavhunga (2012) model

Despite Mavhungas' (2012) model contributions to Topic Specific studies, the model is not without limitations. Firstly, Mavhungas' model is developed from the science domain perspective. Although the principles of Topic Specific model of Mavhunga can be applied to the teaching of specific topics in economics, the findings from Mavhunga's model cannot be applied to economics topics. Consequently, the model failed to illustrate the sub-components to each component as in other empirical TSPCK studies where Topic Specific PCK could be assessed through observation of its sub-components. Our model included sub-components for ease of use to enable a detail analysis of economics teachers' Topic Specific Knowledge to be undertaken. While Mavhungas' interest lies in constructing a tool that measures the quality of Topic Specific PCK of chemistry pre-service teachers at a topic level, our model focuses on how to improve the teaching and learning of specific economics topics like MD through a practicebased Topic-Specific PCK model. It is important to note that the object of analysis of our model is to capture how teachers demonstrate and use the specific knowledge they bring into play when teaching specific topics in the classroom settings and not to measure the quality of Topic Specific as Mavhunga (2012) model focuses on. Another concern with Mavhunga (2012) model is that 
although the model recognizes the specific knowledge needed for transforming the content knowledge in a particular topic, the model is not well supported with pedagogical reasoning and actions to display the transformed knowledge. This means that Mavhungas' model did not provide room for showcasing teachers' teaching practices. Thus, we sought to develop a practice-based Economics Topic-Specific PCK model that will afford teachers the opportunity to engage in pedagogical reasoning and action.

\subsection{Research Question}

The research question that guided this study was:

Can Economics Teachers' Topic Specific Pedagogical Content Knowledge (ETTSPCK) Model be developed for Market Dynamics?

\section{Methodology}

\subsection{Research Design}

This study adopted a descriptive, qualitative case study to examine economics teachers' use of TS-PCK in teaching MD with the purpose of proposing an Economics Teachers' Topic Specific PCK model. The case study approach was chosen to gain an in-depth understanding of how the two participant teachers demonstrated their use of TSPCK in teaching MD thus, presenting a description of each case within the context (Rahman, 2017).

\subsection{Participants}

Two economics teachers were purposively selected from two different schools in Tshwane North District, South Africa. They were selected based on two criteria: The teachers possess at least 5 years of teaching experience in economics at secondary school level and that the teachers have obtained a tertiary education qualification for teaching economics. The teachers teach the 10th and 11th Grades. The Grade 10 teacher had 9 years teaching experience while the Grade 11 teacher had 13 years teaching experience. This criterion is important because our focus is to model experienced teachers' teachings with the assumption that the teachers have already developed TSPCK in teaching MD over the years of teaching. Both teachers hold Bachelor of Science degree in economics and a Postgraduate in Education Certificate (PGCE) in economics. The two teachers were females, not intentionally chosen but chosen according to the set criteria.

\subsection{Instruments}

Lesson observations were used for data collection. Lesson observations were used in order to gain in-depth insight into the situation being observed (Creswell et. al, 2016) and to examine the key Topic Specific pedagogical skills and knowledge demonstrated by the teachers on MD. The lessons were observed with an observation protocols. The observation protocols have two parts. The first part was adapted from Sibuyi (2012) and is made up of the five TSPCK components: Content Knowledge, Curriculum Knowledge, Learners' Prior Knowledge, Teaching Strategies and Knowledge of Representations. These components were used to identify specific elements manifested by the teachers during MD teaching. (See Appendix 1) for more information about the components. The second part of the observation protocol was adapted from Romylos (2018) and contains elements; aims and objectives of MD, learners' 
involvements during the lesson periods, specific teaching strategies used by the teacher while teaching MD, content presented by the teachers, time limit of the lesson, specific classroom activities, and introduction. Although these elements were captured with the video camera, it was easier to immediately tick what was observed.

\subsection{Data Collection and Procedure}

The lesson observation for this study began with researchers' initial visits to the teachers' classrooms to be familiarized with the teacher, learners and the classroom setting. In other words, the researchers' first-two visits to the classrooms come prior to the start of teaching MD. This was done as noted by Noguera (2018) that the presence of an observer in the classroom tend to influence the nature of lesson presentation thus making it untypical of the teachers' usual style of teaching. In the first two visits to the classrooms in all the grades, the researchers did not record the lessons observed. This implies that the topics treated during these first visits fall outside the topic "Market Dynamics". During actual observation, the two economics teachers were observed in their different classroom during normal teaching periods. Four different lessons were observed for both Grade 10 and Grade 11. In all the lessons observed, the researchers sat at the back of the classroom to avoid disrupting the lesson. The researchers also ensured that they got into the classroom before the learners in each lesson period.

All lessons observed were video recorded.Video recording was deemed fit in order to examine the structure of the teaching and learning of MD from the two participant teachers. After the recordings, the videotapes were replayed and the actions of the teachers were watched using the observation protocols. The observation protocols help to examine the key Topic Specific PCK elements manifested by the teachers during the teaching process.

\subsection{Data Analysis}

The analysis of the video recording followed the following process as described by Creswell et al, (2015):

(1) 'Open coding' is the initial coding process that helped the researchers to retrieve quickly all data and text that show commonalities in order to group them in thematic ideas so that each theme can be examined together and different cases compared where necessary.

(2) 'Axial coding' is the second stage of the coding process which entailed putting data in new ways, making explicit connections between categories and searching for relationships and patterns.

(3) 'Selective' coding which involved the process of selecting and identifying the core category and making contrast and comparisons relating to other categories.

(4) Making sense of the data, which involved interpreting and presentation of the data and abstracting the findings from the categories.

During the analysis, the researchers paid particular attention to areas where Topic Specific PCK elements of those teachers were manifested. In order words, the analyses of the video recordings were critically done using the five Topic Specific PCK components. This helped the researchers to identify frequency of 
themes as data were coded under emerging themes. Common themes were grouped into categories, and sub-components were identified from the main TSPCK components. These sub-components together with the components made up the components of our new proposed ET-TSPCK model integrated into the existing Mavhungas' Topic Specific PCK components. We describe the subcomponents that emerged from different themes.

\section{Topic Specific-Content Knowledge (TS-CK) for Market Dynamics teaching}

Topic Specific-Content Knowledge (TS-CK) of economics teachers was grouped under the theme: Knowledge of economics topic 'Market Dynamics', and the following sub-components emerged Horizon Content Knowledge, Specialized Content Knowledge and Common Content Knowledge. These sub-components indicate that economics teachers not only have the subject matter knowledge for MD but could as well use the knowledge to solve learners' problems while learning MD.

\section{Topic Specific Knowledge of Teaching Strategies (TSK-TS) for Market Dynamics} teaching

With respect to Topic Specific Knowledge of Teaching Strategies (TSK-TS), two sub-components emerged Practical Knowledge of MD and Theoretical Knowledge of $M D$ from the theme: Knowledge of instructional strategies. Under teachers' practical knowledge of MD teaching however, our analysis indicated that the lecture methods were predominantly used, as learners seem not to understand the topic when other methods are used.

\section{Topic Specific Knowledge of Representations for Market Dynamics teaching}

Economics teachers' Topic Specific Knowledge of Representation was grouped under the theme: Pedagogical Knowledge. Two knowledge sub-components emerged Knowledge of analogies, and Knowledge of activities. Our analysis shows that all the teachers were able to use analogies to illustrate MD concepts but failed to represent MD concepts with activities.

\section{Topic Specific curriculum Knowledge for Market Dynamics teaching}

Economics teachers' Topic Specific Curriculum knowledge for MD teaching was grouped under the theme: Knowledge of learning objectives and knowledge integration. Our analysis revealed two knowledge components; Vertical and Horizontal curriculum knowledge. The analysis showed that both teachers knew how sub-topics were distributed in the curriculum (Vertical) and the integration of one sub-topic to the other in the entire curriculum (Horizontal).

\section{Topic Specific Knowledge of 'Learner Prior Knowledge' for Market Dynamics teaching}

Economics teachers' Topic Specific Knowledge of 'Learner Prior Knowledge' was examined under the theme: Knowledge of relating new knowledge to existing knowledge. The analysis indicated two knowledge components: learners' misconceptions/pre-conceptions and learners' difficult concepts in previous grades. Our analysis shows that the teachers were not able to easily detect challenges and difficulties learners face in understanding some aspects of the topics learnt in previous grades. 


\section{Topic Specific Beliefs for Market Dynamics teaching}

Teachers' beliefs were not among the TSPCK components identified according to the framework adopted for this research. However, during lesson observations, we observed that the belief factor was significant and had influence on teachers' teaching of MD. Although teachers' beliefs might not be an observable factor, it was evident that the participant teachers placed much value not only on the affective side of their teaching by being humorous, accepting learners as they are, creating a relaxing environment, providing positive feedback and spreading joy, but also by the comments the make during the course of their teaching.

From our analysis, we categorize teachers' beliefs under the theme Teachers' Philosophy about Market Dynamics Teaching, which resulted to the following sub-components: career-related beliefs, self-related beliefs, curriculum-related beliefs, and learner-related beliefs. Our analysis revealed that teachers' beliefs in relation to career-related beliefs showed that the teaching of MD motivates economics teachers' interest of their choice of teaching as career. This was evident by the Grade 10 teachers' comment: "...I never regretted chosen being an economics teacher...I like the fact that I impact knowledge..." Likewise, the Grade 11 teacher also commented: "...I always have joy when I see you learners becoming great economists and economics teachers in future just as I am ..." The teachers believe that their careers as teachers are unique in impacting new knowledge to the young learners. Our analysis also showed in terms of self-related beliefs, that teachers' self-efficacy lead to determination and persistency in the teaching of MD. The Grade 10 teacher commented; "...I will leave no stone unturned until you understand this topic...", while the Grade 11 teacher also commented; "...I know myself, I am a go-getter, I will put in my best to ensure that none of you learners fell this subject even in your Matric exams..." These teachers' comments indeed show their self-efficacy beliefs towards the teaching of MD. In terms of curriculum beliefs, our analysis indicated that the teachers believe that the school curriculum have not achieved much in relation to curriculum specifications and depth of coverage of basic MD concepts for each grade level. This was evident by the teachers' comments about the school curriculum. According to the Grade 10 teacher, "...your curriculum is too broad to cover in a single term as specified...but I will do my best" In addition, the Grade 11 teacher commented; "...MD sub-topics are too broad from the $10^{\text {th }}$ Grade to the $12^{\text {th }}$ Grade, some of the sub-topics could be learnt in your first year in higher institution..." With respect to learners-related beliefs, our analysis indicated that the teachers see their learners as motivating factors that contributed to their successes in teaching MD despite the challenges learners face in understanding MD. This was shown on the teachers' comments. The Grade 10 teacher commented; "...you guys make me proud. Despite how challenging this topic seems to be, I see the zeal in you..." while the Grade 11 teacher also made a similar statement; "...yeah, the topic is not an easy one, but I like your determination..." These teachers' comments were analysed based on their beliefs and our findings indicated that they have implications to the teaching of MD. 


\section{Findings}

The findings of this study lies on the development of the new model. The model is developed from ETSPCK components and sub-components that emerged from the different themes.

\section{The ET-TSPCK model}

The development of the model begins by stating the model assumptions. The first assumption is that the participated economics teachers are experienced with at least 5 years of teaching economics in secondary school. For this reason, we assume the economics teachers have already developed specific knowledge for teaching Market Dynamics but this knowledge were not identified. The second assumption is that economics teachers' Knowledge informs and is informed by Topic Specific PCK. By this, we mean that since Topic Specific PCK is specific to a particular topic, through pedagogical reasoning, the transferability principles of topic-specific PCK (TSPCK) that holds across topics applies for this model and on the topic of Market Dynamics provided that the teachers have the prerequisite content knowledge (Rollnick \& Mavhunga, 2016). The third assumption is that for economics teachers to teach MD, they need specific knowledge. This implies that the teacher must possess a specific knowledge located in each sub-component of the model needed for teaching MD.

ET-TSPCK model is developed from an integrative view similar to other PCK models (Grossman, 1990; Magnusson et. al, 1999). Integrated models according to Kauchak and Eggen (2012) are teaching models that provide structures that guide learners to learn from "organized [bodies] of knowledge...a combination of facts, concepts, generalizations, principles and rules, integrated with one another". Mavhunga (2012) TSPCK components are integrated into ETSPCK components for MD teaching. The integrative perspective was chosen to gain insight into the elements that make up teachers' specific knowledge and to gain understanding of the interaction between the components. The integrative approach was also chosen to enable teachers incorporate different knowledge with different approaches of teaching specific topics into a broader frame that is practically useful.

Using Mavhunga (2012) TSPCK components as the bases in the model development, top-down approach was employed to all the data. Top-down approach is a method use in developing a model by using the big picture and all its components as a basis for decision making whereby the base components become the driving force for the end goal (Ogunlayi \& Britton, 2017; Weißleder \& Lackner, 2013). The model was applied to data from the themes that emerged; Knowledge of economics topic-MD, Knowledge of instructional strategies, Pedagogical knowledge, Knowledge of learning objectives and knowledge of integration, Knowledge of relating new knowledge to existing knowledge and Teachers' philosophy about MD teaching. These themes were derived from different categories to form the basic framework for the model (Top-down). From these emerged themes, we established different sub-components from the main components. 
Our model is then broken down into different domains and sub-domains. The breaking down of domains into more finely defined sub-categories is for the sake of the lessons observed and in order for teachers to reflect on the sort of knowledge required for teaching (Ball, Thames \& Phelps, 2008). The two specific knowledge domains are: Economics Topic Specific (ETS) knowledge and Pedagogical Content Knowledge (PCK). While ETS knowledge gave rise to five knowledge components: Curriculum Knowledge (CmK), Content knowledge (CK), Knowledge of Representations (KoR), Learners' Prior knowledge (LPK), Knowledge of teaching strategies (KTS) and teachers' beliefs (TB) as the sixth component (Top-down), Pedagogical Content Knowledge (PCK) consists of knowledge components that are related to economics content in terms of teaching and learning. These components are: Knowledge of the Context, Knowledge of learners, Content Knowledge and Pedagogical Knowledge. The two-knowledge domain ETS and PCK further gave rise to different subdomains. These sub-domains are:

(i) Knowledge of Economics (E), which includes connections between economics as a subject with other, related topics/subject in the domain (Horizontal and Vertical content knowledge) and the knowledge of didactic principles for teaching economics topics. We describe knowledge of Market Dynamics as what and in what way the economics teachers know the topic they teach (e.g. basic Market Dynamics concepts, principles, laws, assumptions) and their meanings.

(ii) Knowledge of Topic Specific (TS) includes, knowledge of teaching 'Market Dynamics' because it is a specific topic.

(iii) Knowledge of Pedagogy (P) consists of knowledge of different ways of representing specific concepts in a topic. This encompasses teaching strategies and techniques for teaching specific economics topics using activities, analogies, examples etc., and ways of dealing with the limitations that might arise while using them.

(iv) Content Knowledge (CK) is knowledge of the subject and its organizing structure (Shulman 1986). Shulman argued that teachers' knowledge of the subject for teaching should go beyond just knowing the facts and concepts but understanding the organizing principles and structures. In that regard, economics teachers' content knowledge is specific knowledge of Market Dynamics' content and its organizing structure as practiced in a classroom.

These knowledge domain and sub-domain constituted the ETSPCK knowledge that a teacher must have.

ET-TSPCK model is built on ETSPCK components with their sub-components and their inter-relationships are well defined. Content Knowledge consists of Horizon content knowledge, Specialized Content knowledge and Common Content Knowledge. Teaching strategies consists of Practical Knowledge of MD and Theoretical Knowledge of MD. Representation comprises of Analogies and Activities. Curriculum Knowledge has the following sub-components: Horizontal and Vertical Curriculum while Learner Prior Knowledge consists of Learners' misconceptions/pre-conceptions and Learners' difficult concepts in previous grades. Teacher beliefs comprise of Career-related beliefs, Self-related beliefs, Learner-related Beliefs and Curriculum-related beliefs. 
When these knowledge components and its sub-components are put together into different domain and sub-domain, the resultant model is an Economics Teachers' Topic Specific Pedagogical Content Knowledge (ET-TSPCK) model (Figure 2) for Market Dynamics teaching.

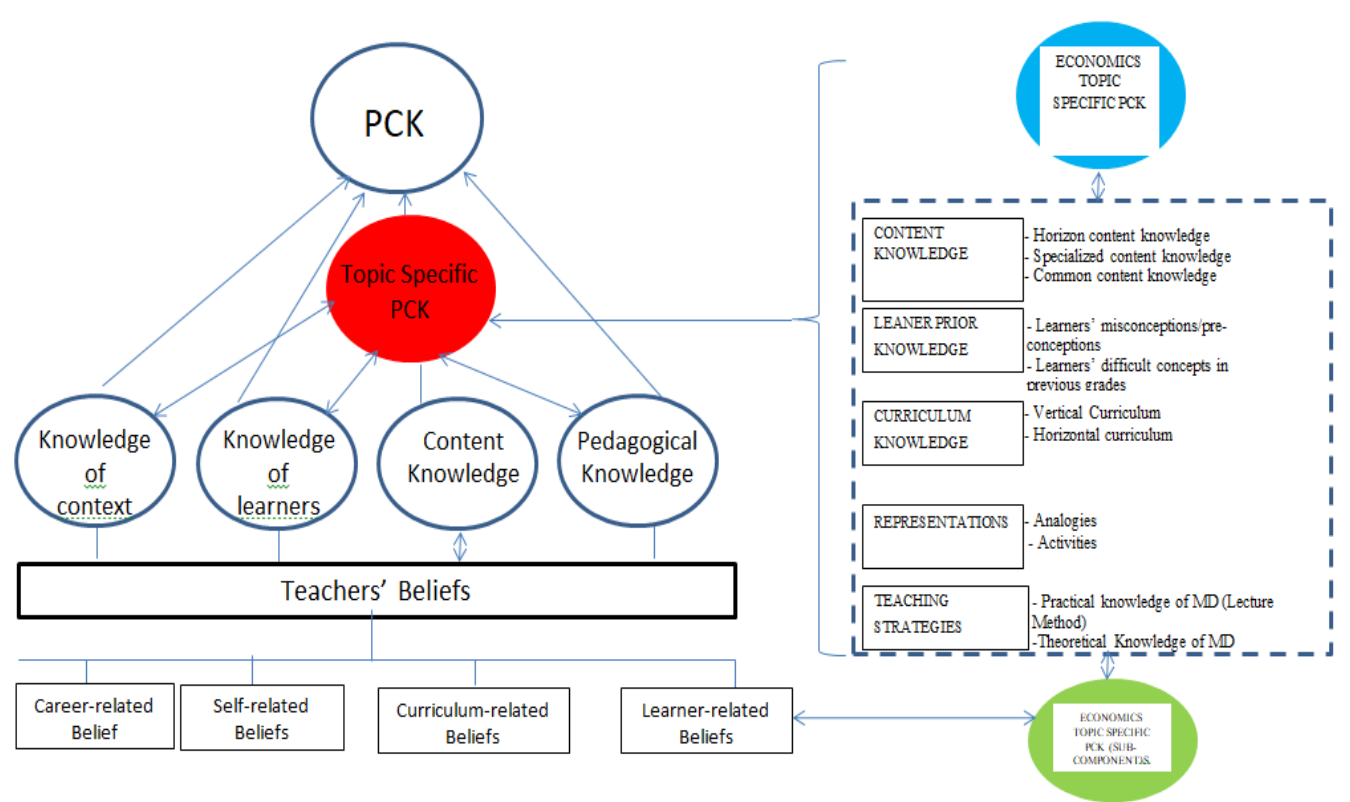

Figure 2: Economics Teachers' Topic Specific Pedagogical Content Knowledge (ETTSPCK) Model

\section{Discussion}

The discussion of our ET-TSPCK model is based on the inter-relationships and interplay among the components. The inter-relationships are discussed to understand how the components interact among themselves within the model. According to Peng (2013) and Veal \& MaKinster (1999), establishing the interrelationship among PCK components is an indication that the development of one component will lead to the development of the other components. ETTSPCK is a holistic model comprising two major domains; the Economic Topic Specific (ETS) domain and the Pedagogical Content knowledge (PCK) domain. We begin our discussion on the ETS domain located at the right side of the model. All components are well-integrated and working together to form the model.

On the right side of the model are the ETSPCK components placed in a frame of context with a dotted line implying that they are context-specific thus, they were observed under the natural classroom settings representing teachers' practices. Our analysis showed that economics teachers had limited knowledge of Learners' Prior Knowledge (LPK) which consists of learners' misconceptions/pre-conceptions and learners' difficult concepts in previous grades. It seems as though learners have previously developed naïve preconceptions of some basic MD concepts that makes it difficult for them to understand the topic. Unfortunately, this has implications for the teachers. 
Teachers find it challenging to identify MD concepts that are challenging to learners from previous grades. Teachers therefore need to help learners come to terms with their pre-conceptions before new knowledge can be built as preconceptions lead to misconceptions when in conflict with economics reasoning. Our analysis shows that the interplay between the sub-components of LPK and Content Knowledge are not mutually connected. This finding echoed Goffe (2013) findings who identified initial misconceptions of micro concepts among students in macro principles classes caused by learners' weak prior knowledge of basic macro-economic concepts.

In terms of Content Knowledge, our analysis indicated that economics teachers use Horizon Content Knowledge (HCK), Specialized Content Knowledge (SCK) and Common Content Knowledge (CCK) to teach Market Dynamics. With respect to $\mathrm{HCK}$, this finding implies that economics teachers understand how topic-specific are related to other topics in previous grades. In other words, economics teachers had the knowledge needed for teaching MD in a continuous way. Our model shows that the inter-relationship that exists among HCK, LPK and $\mathrm{CmK}$ appears to be reciprocal. This inter-relationship was evident as teachers were able to connect to topics in other grades curriculum. Teachers were also able to understand learners' misconceptions and difficulties from other grades levels. This finding corresponds to Ayers (2016) who found that economics teachers used HCK to make connections to content in other grades.

Regarding SCK, our analysis shows that economics teachers possess a specialised kind of knowledge that pertains exclusively to the ambit of MD teaching, which is not found in other economics topics. The model shows that the interplay among SCK, Knowledge of Representations and teaching strategies are related. This finding explains the ability of economics teachers to put into practice, the explanation of MD concepts in a much easier way in which they conceptualized them. With a specialized knowledge, economics teachers were able to identify the right teaching strategy and the correct form of representation suitable to explain a particular concept of MD. This finding is in line with the findings from Aguilar-González, Muñoz-Catalán and Carrillo (2019) who found a connection between a primary school teachers' conception of mathematics and specialized content knowledge.

Our analysis indicated that economics teachers possess Common Content Knowledge (CCK) for teaching MD. CCK for economics teachers means knowledge of MD and skills that are not really unique to teaching MD. Our findings show that economics teachers have the general knowledge of basic MD concepts that look 'common' per se to learners. These common concepts most times however, erroneously explain economic phenomena. As such, when learners fail to understand the economic meanings of those concepts, it negatively influences their understanding of MD. The model shows that the interplay among CCK, LPK and Curriculum Knowledge is well connected. Our finding is in line with Hurrell (2013) who argued that teachers ought to have basic Common Content knowledge of concepts in a subject in order to teach better. 
Another finding from our analysis revealed that teachers use Vertical and Horizontal knowledge of curriculum to teach MD. Horizon curriculum knowledge for MD teaching is the ability of economics teachers to connect what learners have learnt in lower grades to what they are about to learn. Vertical curriculum knowledge on the other hand means that the Economics teachers had knowledge of what has been taught previously in MD topics and what will be taught in the future within the same topic. Our model shows that the interrelationship between teachers' curriculum knowledge components and teachers Content knowledge components is related. Vertical and Horizontal curriculum knowledge integration is supported by Alghazo (2015) who argues that integration of curriculum not only makes learning more relevant and provides learners with a learning environment but that it also promotes learning of basic concepts available for use in context. Economics teachers showed good knowledge of representations in the form of analogies. Analogies gave economics learners insight into concepts that are being represented with something similar. Our finding is similar to that of Cruz-Hastenreiter (2015), who argues that the students gained insight with analogies and it helped to highlight learners' misconceptions. Our findings also concur with that of Ogbonnaya et al, (2020) who found that economics teachers demonstrated good use of Topic Specific PCK with the use of analogies in teaching MD. There is strong link between analogies and curriculum knowledge in the model. The link is not a surprised as CAPS economics specified some analogies that could be used to illustrate the meaning of some MD concepts. However, on the use of activities, there was no link between the use of activities and curriculum knowledge. The finding was evident as teachers struggle to find adequate activities to represent MD concepts. Economics teachers have criticized the CAPS curriculum for providing inadequate activities that could easily be used to explain difficult concepts in MD. Our model however shows a direct link instead of a revised link between teachers' Knowledge of representations and Curriculum, perhaps because the use of activities were not sufficiently put in use. This finding is contrary to Khandves' (2016) who found the use of activities as interactive teaching that promote active learning, heighten attention and motivation.

Our analysis indicated that economics teachers demonstrated good use of teaching strategies in the form of Practical and Theoretical knowledge to teach MD. This implies that the teachers have good understanding of the theories behind MD and put them in practical use. However, the finding that teachers predominantly make use of lecture methods implies that even though economics teachers' have developed teaching strategies and put them into use, the teaching strategies may either not have been fully developed or may not have been put to use in a rational way. The teachers should explore alternative methods of teaching MD. This finding is not a surprise as teachers most often do not check the type of teaching strategy stipulated in the curriculum rather teachers claim that learners do not understand the topic when using other methods of teaching other than the lecture method. Our model shows that the interplay among the components of teaching strategies, the components of Curriculum knowledge 
and content knowledge are not well connected. This finding is contrary to Aguilar-González, Muñoz-Catalán and Carrillo (2018) whose teachers' practical knowledge of Mathematics was demonstrated in a procedural ordered and precise way using different teaching methods when teaching mathematics.

On the left side of our model is the PCK domain. A close look at the model shows that Content Knowledge appears on both side of the model. This implies that adequate content knowledge of $\mathrm{MD}$ is a necessary condition for MD teaching. Our analysis showed that largely, economics teachers use their Topic Specific knowledge in relation to their Content Knowledge to solve learners' problems in MD. This was shown by the use of a single line instead of a double arrow as in Mavhungas' (2012) model (Figure 1). The single line in our model shows a direct relationship between Content Knowledge of economics teachers and their topic Specific Knowledge of MD. The direct relationship exists because the teachers demonstrated sufficient use of Topic Specific PCK in content when teaching Market Dynamics. Similarly, with respect to teachers' beliefs, our model shows that economics teachers' beliefs are the over-arching components that seem to control the decisions made by the teachers while teaching Market Dynamics. For example, teachers' self-determination (self-related beliefs) pushes them to put more effort in teaching in order for learners to understand. This is shown with reverse double arrows in opposite directions showing a reciprocal relationship linking teachers' beliefs to content knowledge while Lines instead of arrows as used in Mavhungas' model link teachers' beliefs to other knowledge components; Knowledge of context, knowledge of learners and pedagogical knowledge. Teachers' belief in our model reveals teachers' personal purposes for teaching, their values and understanding about the topic. The interplay among teachers' beliefs with its sub-components and the main components (content knowledge, curriculum, learner prior knowledge, representations and teaching strategies) with their sub-components are well connected. Knowledge of students in our adopted model is replaced with knowledge of learners because the teachers focus is on the learners.

The faint double arrow as supposed a thick single arrow in Mavhungas' model that runs from Pedagogical Knowledge to TSPCK showed that although a relationship exists between them, the relationship is weak and reciprocal. It could also be that economics teachers' pedagogical knowledge depends largely on the teachers' beliefs or on the nature of the topic. Perhaps, that explains the reason the teachers prefer the use of teacher centred-lecture method in teaching Market Dynamics. This argument is in agreement with Friedrichsen, Kathryn and Teuscher, (2010) who states, "if the teachers believe that students learn best through listening, then the teacher will likely choose lectures as the most appropriate strategy". However, the choice of the best teaching strategy between teacher-centred and learner-centred instructional practices remains a controversial argument. According to Watts and Walstad (2010), no instructional practice has been proven more effective than others have when teaching economics topics. The thick double arrows that connect teachers' knowledge of learners to TSPCK show that there exists a strong relationship between them. This is because economics teachers' knowledge of learners is a function of their 
knowledge about learners' learning difficulties, the conceptions, pre-conceptions and misconceptions about the topic.

Furthermore, while Mavhungas' model did not indicate any relationship to exist between TSPCK and knowledge of the context, our new model shows that a direct relationship exists between them because teachers' use of Topic Specific PCK is observed through lessons delivered in the classroom context. Finally, a direct relationship exists between the main components, Topic Specific PCK and other knowledge domains shown with the longer red arrow.

The interplay among our ETSPCK components and its' sub-components seem contrary to the literature assertions by Peng (2013) \& Veal and MaKinster (1999) that the development of one component will lead to the development of the other components. In our model, though we assumed that all the teachers have developed Topic Specific PCK however, efficient use of one component does not guarantee efficient use of the other components. Our findings about the interplay among the components fall in line with Park and Oliver (2008) claim that "Lack of coherence among the components would be problematic within an individual's developing PCK and increased knowledge of a single component may not be sufficient to stimulate change in practice".

Understanding the complexity of the inter-relationships and the interplay among the components and the sub-components of our model is useful in facilitating the teaching of not only Market Dynamics but also other specific topics in economics.

\section{Conclusion}

This research focused mainly on developing an economics model for teaching MD, thus ET-TSPCK model was developed. The model was developed from an integrative view and described the inter-relationships that existed among the components. Based on the developed model, this research has contributed to economics education literature on Topic Specific models for MD teaching and the teaching of other topic economics specific using the transferability principles. The development of ET-TSPCK model is new and has filled the gap of absence of a seemingly valid model for economics teachers to reflect on in order to improve the teaching of MD. ET-TSPCK model is recommended for both Preservice teachers and in-service economics teachers on the teaching of MD. The findings of this study are recommended as reference to the Department of Basic education in their curriculum development. Further research could be conducted on the nature of teachers' TSPCK for teaching MD with reference to the results of this study.

\section{Acknowledgement}

The National Research Foundation (NRF) supported this research. 


\section{References}

Akinyemi, O. S. (2016). Pre-Service Teachers' Development of Topic Specific PCK in kinematics and transferability of PCK competence to a New Physics Topic [Dissertation]. University of the Witwatersrand, Johannesburg, South Africa.

Alghazo, S. (2015). The role of curriculum design and teaching materials in pronunciation learning. Research in Language, 13(3), 316-333. https://doi.org/10.1515/rela-2015-0028

Aguilar-González, A., Catalán, M. C., \& Carrillo, J. (2019). An example of connections between the mathematics teacher's conceptions and specialised knowledge. EURASIA. Journal of Mathematics, Science and Technology Education, 15(2), 1-15. https:// doi.org/10.29333/ejmste/101598

Aguiló, P., Sard, M., \& Tugores, M. (2016). Price discrimination: A classroom experiment. The Journal of Economic Education, 47(2), 132-139. https://doi.org/10.1080/00220485.2016.1146095

Aydin, S., Friedrichsen, P. M., Boz, \& Hanuscin, D. L. (2014). Examination of the topicspecific nature of pedagogical content knowledge in teaching electrochemical cells and nuclear reactions. Chemical Education Research, 15(658), 1-17. https://doi.org/10.1039/c4rp00105b

Ayers, C. A. (2016). Developing pre-service and in-service teachers' pedagogical content knowledge. Social Studies Research and Practice, 11(1), 73-92.

Ayers, C. A. (2015). A qualitative study of the pedagogical content knowledge and personal orientations toward economics of award-winning secondary economics teachers. [Unpublished Doctoral Dissertation]. The University of North CarolinaGreensboro.

Ball, D. L., Thames, M. H., \& Phelps, G. (2008). Content knowledge for teaching: what makes it special? Journal of teacher education, 59(5), 389-407. https://doi.org/10.1177/0022487108324554

Carlsen, W. (1999). Domains of teacher knowledge. In J. Gess-newsome and N. G. Lederman (eds.) Examining pedagogical content knowledge. Science \& technology education library, 6 . Springer.

Cochran, K. F, DeRuiter, J. A., \& King, R. A. (1993). Pedagogical content knowing: an integrative model for teacher preparation. Journal of teacher Education, 44(4), 263273. https:// doi.org/10.1177/0022487193044004004

Creswell, J. W., Ebersohn, L., Eloff, I., Ferreira, R., Ivankova, N. V., Jansen, J. D., Nieuwenhuis, J., Pietersen, J., \& Plano Clack, V. L. (2016). First step in research 2. Second Edition. Van Schaik Publishers.

Cruz-Hastenreiter, R. (2015). Analogies in high school classes on quantum physics. Procedia - Social and Behavioral Sciences, 167(2015), 38-43. https://doi.org/10.1016/j.sbspro.2014.12.639

De Jager, C. (2015). Investigating a mechanism for transfer of topic-specific pedagogical content knowledge in a new chemistry topic. Dissertation: University of the Witwatersrand, Johannesburg, South Africa.

Department of Basic Education (DBE) (2015). National senior certificate diagnostic report. Pretoria. Government Printer.

Department of Basic Education (DBE) (2016). National senior certificate diagnostic report. Pretoria. Government Printer.

Department of Basic Education (DBE) (2018). Report on the 2019 national senior certificate examination. Pretoria. Government Printer.

Department of Basic Education (DBE) (2020). Report on the 2019 national senior certificate examination. Pretoria. Government Printer. 
Feiman-Nemser, S. (2001). Helping novices learn to teach: lessons from an exemplary support teacher. Journal of Teacher Education, 52(1), 17-30. https://doi.org/10.1177/0022487101052001003

Fourie, A., \& Krugell, W. (2015). Determining the economic literacy of introductory economic students in South Africa. International journal of economic education and development, 6(1), 86-96.

Friedrichsen, P., Kathryn, B., \& Teuscher, C. D. (2010). Strategies and sources of support for beginning teachers of science and mathematics. Journal of Applied Social psychology, 107(5), 169-181. https:// doi.org/10.1111/j.1949-8594.2007.tb17781.x

Gess-Newsome, J., \& Lederman, N. G. (1999). Examining pedagogical content knowledge: the construct and its implications for science education (3-17). Boston: Kluwer.

Grossman, P. L. (1990). The making of a teacher: Teacher knowledge and teacher education. New York: Teachers College Press.

Goffe, W. L. (2013). Initial Misconceptions in Macro Principles Classes. Retrieved from http://cook.rfe.org/misconceptions.pdf

Hurrell, D. P. (2013). What Teachers Need to Know to Teach Mathematics: An argument for a reconceptualised model. Australian Journal of Teacher Education, 38(11), 5464. http://dx.doi.org/10.14221/ajte.2013v38n11.3

Kauchak, D., \& Eggen, P. (2012). Learning and teaching. Research-based methods $6^{\text {th }}$ edition. New Jersey: Pearson.

Kistner, S., Rakoczy, K., Otto, B., Klieme, E., \& Büttner, G. (2015). Teaching learning strategies: The role of instructional context and teacher beliefs. Journal for Educational Research Online, 7(1), 176-197.

Khandve, P. V. (2016). Interactive teaching and learning activities. In Proceedings of ISTE the 5th Annual National Convention and International Conference on Challenges and Opportunities in Technical Education in era of Sustainable Development. H.V.P. Mandal's College of Engineering \& Technology, India.

Kruger, D. (2018). Teacher educators' perspectives on pedagogical content knowledge for secondary school economics teaching [Masters Dissertation]. North-West University, South Africa.

Kuhn, C., Alonzo, A., \& Zlatkin-Troitschanskaia, O. (2016). Evaluating the pedagogical content knowledge of pre-and in-service teachers of business and economics to ensure quality of classroom practice in vocational education and training. Empirical Research in Vocational Education and Training, 8(5), 1-18. https://doi.org/10.1186/s40461-016-0031-2

Korstjens, I., \& Moser, A. (2018). Series: practical guidance to qualitative research. part 4. trustworthiness and publishing. European Journal of General Practice, 24(1), 120124. https://doi.org/10.1080/13814788.2017.1375092

Mankiw, N. G. (2015). Principles of MacroEconomics, 7E. Mason, OH: Cengage Learning.

Magnusson, S., Krajcik, J., \& Borko, H. (1999). Nature, sources, and development of pedagogical content knowledge for science teaching. In J. Gess-Newsome \& N. G. Lederman (Eds.), Examining pedagogical content knowledge: the construct and its implications for science education, pp. 95-132. Dordrecht: Kluwer Academic.

Malyshkin, V. G. (2016). Market Dynamics. On supply and demand concepts. Loffe Institute, Politekhnicheskaya. Russia Mavhunga, M. E. (2012). Explicit inclusion of topic specific knowledge for teaching and the development of pck in pre-service science teachers. [Doctoral thesis]. University of the Witwatersrand, South Africa.

Mavhunga, E., \& Rollnick, M. (2016). Can the principles of topic specific PCK be applied across science topics? Teaching PCK in a pre-service programme. In $\mathrm{N}$. Papadouris, A. Hadjigeorgiou \& C. P. Constantinou (Eds.) Insights from 
Research in Science Teaching and Learning. Contributions from Science Education Research, vol 2., pp. 56-72. Springer, Cham. https://doi.org/10.1007/978-3-319-20074-3_5

Ng, S. F., \& Chan, O. K. K. (2014). A preliminary study on the development of pedagogical content knowledge among economics and primary social studies student teachers in singapore. HSSE Online, 3(1), 25-36.

Noguera, J. S. (2018). The role of classroom observation in pre-service English teachers' understanding of the teaching profession. Porta Linguarum, 30, 193-206.

Ogbonnaya, I. C., Mji, A., Mafa-Theledi, O. N., \& Ngulube, B. (2020). Economics teachers' use of topic specific pedagogical content knowledge in teaching market dynamics. Problems of Education in the 21st Century, 78(3), 371-393. https://doi.org/10.33225/pec/20.78.371

Ogunlayi, F., \& Britton, P. (2017). Achieving a 'top-down' change agenda by driving and supporting a collaborative 'bottom-up' process: case study of a large-scale enhanced recovery programme. BMJ Journals, 6(2). https://doi.org/10.1136/bmjoq-2017-000008

Park, S., \& Oliver, S. (2008). Revisiting the conceptualization of pedagogical content knowledge (PCK): PCK as a conceptual tool to understand teachers as professionals. Research in Science Education, 38, 261-284. https:// doi.org/10.1007/s11165-007-9049-6

Park, S., Jang, J. Y., Chen, Y. C., \& Jung, J. (2011). Is pedagogical content knowledge (PCK) necessary for reformed science teaching? Evidence from an empirical study. Research in Science Education, 41, 245-260.

Peng, W. (2013). Examining pedagogical content knowledge (PCK) for business English teaching: concept and model. Polyglossia, 25, 83-94.

Rahman, M. S. (2017). The advantages and disadvantages of using qualitative and quantitative approaches and methods in language "testing and assessment" research: a literature review. Journal of Education and Learning, 1(6), 102-112.

Rollnick, M., \& Mavhunga, E. (2016). Can the principles of topic-specific PCK be applied across science topics? Teaching PCK in a pre-service programme. In N Papadouris, A. Hadjigeorgiou \& C. Constantinou (eds.), Insights from Research in Science Teaching and Learning. Springer.

Romylos, S. (2018). Knowledge and identities: the relation between professional identities and PCK (pedagogical content knowledge) [Doctoral Thesis]. North-West University, South Africa.

Shulman, L. (1986). Those who understand: knowledge growth in teaching. Educational Researcher, 15(2), 4-14.

Sibuyi, C. D. (2012). Effective teachers' pedagogical content knowledge in teaching quadratic functions in mathematics [Dissertation]. University of Pretoria, Pretoria, South Africa.

Veal, W. R., \& Makinster, J. G. (1999). Pedagogical content knowledge taxonomies. Electronic Journal of Science Education (Revista de Educacion en Ciencias), 3(4).

Watts, M., \& Walstad, W. B. (2010). Economic Education in an International Context. The Journal of Economic education, 41(4), 410-412. https:// doi.org/10.1080/00220485.2010.510407

Weißleder, S., \& Lackner, H. (2013). Top-down and bottom-up approach for modelbased testing of product lines. Electronics proceedings in theoretical computer science. In A. Petrenko \& H. Schlingloff (eds.), Eighth Workshop on Model-Based Testing. EPTCS 111, (pp. 82-94). https://doi.org/10.4204/EPTCS.111.7

Zuidhof, P. (2014). Thinking like an economist: The neoliberal politics of the economics textbook. Review of Social Economy, 72(2), 157-185 https://doi.org/10.1080/00346764.2013.872952 


\section{Appendix 1}

\section{Lesson Observation Protocols}

Lesson Observation Protocol 1

\begin{tabular}{|c|c|c|}
\hline $\begin{array}{c}\text { TSPCK element to be } \\
\text { observed }\end{array}$ & Evident when the teacher.... & $\begin{array}{c}\text { Observed practice } \\
\text { displayed }\end{array}$ \\
\hline $\begin{array}{l}\text { 1. learner prior } \\
\text { knowledge }\end{array}$ & $\begin{array}{l}\text { 1. Exhibits deep and thorough } \\
\text { conceptual understanding of } \\
\text { identified aspects of Market } \\
\text { Dynamics. } \\
\text { 2. Identifies critical Economics } \\
\text { components within the topic that } \\
\text { are fundamental for understanding } \\
\text { and applying the concepts in } \\
\text { Market Dynamics. } \\
\text { 3. Displays skills for solving problems } \\
\text { in the area of Market Dynamics. } \\
\text { 4. Addresses learners' misconceptions } \\
\text { 5. Displays expectations of possible } \\
\text { difficulties learners may face } \\
\text { during learning and address such. } \\
\text { 6. Discusses learners' ways of } \\
\text { thinking about a concept. } \\
\text { 7. 7. Taps into learners prior } \\
\text { knowledge to clarify expected } \\
\text { difficulties }\end{array}$ & \\
\hline 2. curricular saliency & $\begin{array}{l}\text { 1. } \begin{array}{l}\text { Observe if teacher displays } \\
\text { horizontal and vertical connections } \\
\text { of curriculum. }\end{array} \\
\text { 2. knowledge of curriculum activities, } \\
\text { projects and programs } \\
\text { 3. Ordering of topics in the } \\
\text { curriculum-does he/she adheres } \\
\text { strictly to the order of topics in the } \\
\text { curriculum or makes adjustments } \\
\text { 4. Identifies/recognises relationships } \\
\text { between concepts, state goals and } \\
\text { curriculum goal/objectives, how } \\
\text { often does she refer to textbook as a } \\
\text { guide to curriculum etc. }\end{array}$ & \\
\hline
\end{tabular}




\begin{tabular}{|c|c|}
\hline $\begin{array}{ll}\text { 2. } & \text { content } \\
\text { knowledge }\end{array}$ & $\begin{array}{l}\text { 1. How does she/he define or } \\
\text { construct MD concepts? } \\
\text { 2. Does he/she identify and lay } \\
\text { emphasis on the more important } \\
\text { objectives, what needs to/needs } \\
\text { not to be assessed } \\
\text { 3. Does he/she assess end results or } \\
\text { the process of the teaching? } \\
\text { 4. Does the teacher method of } \\
\text { assessment match the topic treated } \\
\text { 5. Body language: does she identify } \\
\text { confusion or agreements from } \\
\text { learners' faces, through nodding of } \\
\text { heads etc. } \\
\text { 6. Demonstrates specialized, common } \\
\text { and horizon content knowledge of } \\
\text { Market Dynamics. } \\
\text { 7. Applying Economics content to } \\
\text { everyday lives relating content to } \\
\text { current news/events. } \\
\text { 8. Demonstrates multidisciplinary } \\
\text { and interdisciplinary knowledge }\end{array}$ \\
\hline $\begin{array}{ll}\text { 3. } & \begin{array}{l}\text { knowledge of } \\
\text { representations }\end{array}\end{array}$ & $\begin{array}{l}\text { 1. Integrates representations into } \\
\text { teaching } \\
\text { 2. Uses examples, analogies, graphs to } \\
\text { represent and show important facts } \\
\text { 3. Uses real life examples to } \\
\text { demonstrate important points } \\
\text { 4. Uses appropriate activities in } \\
\text { Instruction }\end{array}$ \\
\hline $\begin{array}{ll}4 . & \text { Teaching } \\
& \text { strategies. }\end{array}$ & $\begin{array}{l}\text { 1. Uses most effective teaching } \\
\text { strategies that march the topic } \\
\text { 2. Uses alternative strategies where } \\
\text { necessary } \\
\text { 3. The teacher makes an instructional } \\
\text { decision that alters the flow of the } \\
\text { classroom by asking a question or } \\
\text { directing learners to perform a } \\
\text { particular task. } \\
\text { 4. Uses real-life examples and } \\
\text { analogies in instruction } \\
\text { 5. Utilises different instructional } \\
\text { strategies in presentations }\end{array}$ \\
\hline
\end{tabular}

Adapted from Sibuyi (2012) 
Lesson Observation Protocol 2

\begin{tabular}{|c|c|c|c|c|c|}
\hline & 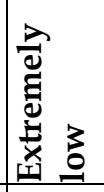 & 芆 & : & 要 & 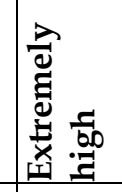 \\
\hline 1. Aims and objectives & & & & & \\
\hline 2. Introduction of topic & & & & & \\
\hline 3. Presentation of the lesson & & & & & \\
\hline 4. Specific teaching strategies & & & & & \\
\hline 5. Time limit of the lesson & & & & & \\
\hline 6. Content presented & & & & & \\
\hline 7. Teaching atmosphere & & & & & \\
\hline 8. Specific classroom activities & & & & & \\
\hline 9. Teacher talk time & & & & & \\
\hline 10. Resources used & & & & & \\
\hline 11. Subject expertise & & & & & \\
\hline 12. Challenges learners to think criticall & & & & & \\
\hline 13. Responds appropriately to learners' & & & & & \\
\hline $\begin{array}{l}\text { 14. Verbal communication: clarity of } \\
\text { speech, tone and pace }\end{array}$ & & & & & \\
\hline $\begin{array}{l}\text { 15. Non-verbal communication } \\
\text { skills: body language, } \\
\text { movements, and gestures }\end{array}$ & & & & & \\
\hline 16. Humor & & & & & \\
\hline 17. Learner attention and participation & & & & & \\
\hline
\end{tabular}

Adapted from Romylos (2018). 